\title{
Towards a Modeling Method for Business Process Oriented Organizational Life Cycle Assessment
}

\author{
Andreas Fritsch \\ Institute AIFB \\ Karlsruhe Institute of Technology \\ Karlsruhe, Germany \\ andreas.fritsch@kit.edu
}

\begin{abstract}
Organizations need to analyze and understand the social, environmental and economic impacts of their operations. Sustainable Business Process Management techniques may provide the necessary visibility of organizational operations and impact hot-spots. However, existing approaches lack a rigorous and comprehensive understanding of sustainability. This paper describes a doctoral research project with the goal to develop a modeling method for Sustainable Business Process Management, that is based on life cycle thinking and integrates Organizational Life Cycle Assessment concepts. A research agenda is described, as well as current intermediary results and next steps.
\end{abstract}

\section{CCS CONCEPTS}

- Applied computing $\rightarrow$ Business process modeling; Enterprise modeling.

\section{KEYWORDS}

Sustainable Business Process Management, Modeling Methods, Organizational Life Cycle Assessment

\section{ACM Reference Format:}

Andreas Fritsch. 2020. Towards a Modeling Method for Business Process Oriented Organizational Life Cycle Assessment. In 7th International Conference on ICT for Sustainability (ICT4S2020), June 21-26, 2020, Bristol, United Kingdom. ACM, New York, NY, USA, 4 pages. https://doi.org/10.1145/3401335. 3401360

\section{MOTIVATION AND RESEARCH OBJECTIVE}

Conventional Business Process Management (BPM) provides concepts and tools to improve the economic performance of organizations [19]. However, to respond to the challenges of Sustainable Development, organizations need to find a balance between environmental, economic and social considerations [5]. While BPM scholars have started to consider sustainability aspects (see e.g. [19], [4], [23]), a comprehensive modeling method for Sustainable BPM is still missing. Moreover, existing efforts are largely constrained to a limited sustainability perspective that, for example, takes only isolated indicators into account [4]. A limited sustainability perspective bears the risk of burden shifting, where a potential

ICT4S2020, fune 21-26, 2020, Bristol, United Kingdom

(C) 2020 Copyright held by the owner/author(s). Publication rights licensed to ACM.

This is the author's version of the work. It is posted here for your personal use. Not for redistribution. The definitive Version of Record was published in 7th International Conference on ICT for Sustainability (ICT4S2020), June 21-26, 2020, Bristol, United Kingdom, https://doi.org/10.1145/3401335.3401360. improvement in one indicator may provoke deterioration in another (e.g., trading a reduction in carbon emissions for increased water use). The same applies, if a sustainability analysis does only consider business processes within one organization, as up- and downstream emissions may take up more than $75 \%$ of the emissions that can be attributed to an organization [8].

This paper describes a doctoral research project that addresses this issue by developing a modeling method for Sustainable Business Process management, that is informed by Organizational Life Cycle Assessment (O-LCA). First, background on Sustainable BPM and O-LCA is given. Then, the concrete research approach is described and justified. The paper closes with an overview of existing preliminary results and immediate next steps.

\section{BACKGROUND}

\subsection{Business Process Modeling}

Conventional Business Process Management (BPM) is concerned with the economic performance of organizations by improving business processes in terms of cost, quality, time and flexibility [19]. The modeling of an organization's business processes is a prerequisite for in-depth analysis and improvement measures, as it creates visibility of existing processes and allows for their (re)design [21]. Various modeling languages, such as BPMN, EPC, and Petri Nets, are available and differ in terms of expressiveness, simplicity and formal analysis capabilities [14].

A modeling method provides guidance for creating useful models [22]. Karagiannis and Kühn [12] distinguish between modeling language, procedure and mechanisms as components of a modeling method. The modeling language provides the elements that can describe a model. The procedure describes steps for using the modeling language, while mechanisms provide additional functionality to use and evaluate the created models. An example for a business process modeling method is the Horus method [22]. It defines several phases for a modeling project from preparation to application, and different modeling facets (e.g. a strategy model, a key figure model, a process model) to provide an integrated view on business processes and their organizational context.

\subsection{Organizational Life Cycle Assessment}

Organizational Life Cycle Assessment (O-LCA) is a multi-impact sustainability assessment approach for organizations [9, p. 19]. It aims to compile and evaluate all "inputs, outputs, and potential environmental impacts of the activities associated with the organization as a whole or portion thereof adopting a life cycle perspective" [10]. In this context, taking a life cycle perspective means, that not only 
the direct inputs and outputs are considered, but one strives to evaluate the full supply chain (beginning with extraction of raw materials that are used for the organization's products and ending with their final disposal or recycling). The corresponding ISO standard [10] and guidelines [9] focus on the environmental dimension of sustainability, however, an adaptation to social sustainability assessment is possible [15].

\subsection{Synopsis of O-LCA and BPM}

BPM scholars have started to take sustainability into consideration under the term "Green" or "Sustainable" BPM. While several approaches to adapt or extend existing modeling languages for Sustainable BPM exist [23], a comprehensive modeling method, that guides users in taking a life cycle, multi-impact perspective is missing. So far, one can observe a strong focus on the environmental dimension of sustainability, singular indicators like energy use and carbon emissions [4]. Often, it is assumed that improving one business process will lead to a more sustainable organization (see e.g. [24]), or that isolated interventions, like process automation or the use of cloud computing will result in overall better environmental performance (see e.g. [20]). As laid out in the introduction section, this needs to be questioned, as without considering multiple impacts along the whole life cycle, an improvement for one indicator in one process step, may well provoke degraded environmental (or social) performance somewhere else in the supply chain.

Taking these observations into consideration, on the one hand, it appears necessary that future Sustainable BPM research learns from environmental sciences [4]. O-LCA with its rigorous understanding of sustainability and strong tradition [2] may provide a useful conceptual frame for such efforts. On the other hand, BPM may provide the concepts and tools to support O-LCA practitioners in gaining insight into internal operations, which is a central goal of an O-LCA study [9, p. 31].

\section{RESEARCH APPROACH}

\subsection{Research Objective}

The goal of the research project is to develop a modeling method for Business Process Oriented Organizational Life Cycle Assessment (POLCA). The two guiding principles are (1) business-process orientation and (2) life cycle perspective. Hereby, business-process orientation means, that the design leverages conventional BPM concepts to provide visibility of business processes and analysis capabilities. Taking a life cycle perspective means, that O-LCA provides the conceptual frame for the understanding of sustainability. More specifically, the research project results in a modeling tool that implements a modeling language, procedure and supporting mechanisms for sustainable business process modeling. The expected utility for the users (Process Managers, Sustainability Consultants) encompass representation of knowledge regarding an organization's sustainability performance, improved decision support, and means for communicating corporate social responsibility efforts with external stakeholders.

\subsection{Research Agenda}

The need to find an appropriate balance between relevance and rigor, i.e. to solve problems of practitioners, while making theoretical contributions [25, p. 38], is especially important for research in the field of Sustainable BPM [4]. Thus, the research agenda takes inspiration from appropriate research frameworks like Agile Modeling Method Engineering [11] and Domain-Specific Modeling Language Design [6]. As practitioner collaboration is especially valuable for future research in Sustainable BPM [4], principles and insights from the related field of Action Design Research [25] are considered. It can be understood as an IT-dominant [25, p. 42], development centered [17] research project.

Table 1: Research Stages

\begin{tabular}{lll}
\hline Stage & Outcome & Methods \\
\hline Diagnosis & Problem Descrip- & (Systematic) Literature \\
& tion & Review \\
Design & Concepts, & Requirements Analysis, \\
& $\begin{array}{l}\text { Design Principles, } \\
\text { Requirements, }\end{array}$ & Language Specification \\
& Metamodels & \\
Implementation & Modeling Tool & Prototyping, Software \\
& Refined Problem & Case Study, Survey \\
Evolution & Description and & \\
& Requirements & \\
\hline
\end{tabular}

Table 1 gives an overview of the different stages of the research project, following a structure proposed by [17]. In the diagnosis stage, the to-be-solved problem is described based on a (systematic) literature review. In the design stage, basic concepts, requirements and metamodels are developed that are then implemented in a modeling tool. In the evolution stage, the previous outcomes are evaluated. The evaluation results inform further developments.

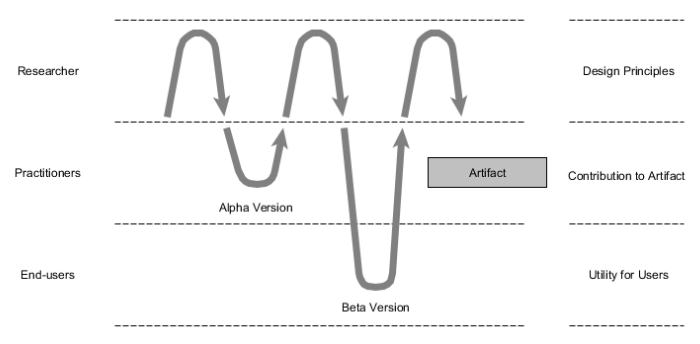

Figure 1: IT-Dominant research schema (based on [25])

As visualized in figure 1, these stages are not strictly sequential and the research agenda encompasses two research cycles. The first cycle results in an alpha version of the modeling tool, comprising the initial set of outcomes. The initial design is guided by literature on business process modeling and O-LCA. The alpha version is evaluated formatively with potential end-users like sustainability 
consultants and BPM managers. The learnings from this evaluation are formalized to adapt the design principles and to guide the development of a beta version of the modeling tool. Finally, the beta version is subject to a summative evaluation. Appropriate evaluation methods may be case studies or surveys [26].

\section{RESULTS TO DATE}

\subsection{Previous Work}

The author has previously worked on modeling languages for sustainability ([1], [18]), contributed to the conception of LCA technologies [3], and the development of a social LCA analysis tool (see https://fairtronics.org). These efforts can be seen as a pre-alpha cycle of the research project and gained insights flow into the design of the POLCA-method.

\subsection{Current State}

The doctoral research project is currently in the alpha cycle of the outlined research schema. The design of the alpha version of the POLCA-method is guided by the following design principles:

Multi-facet Modeling Business process modeling methods like Horus provide multiple modeling facets to express, for example, the interlinkages between dynamic and static organizational structures. Based on the goal of the POLCAmethod to support sustainability assessment and management, it should support the modeling of relevant facets like business processes (which activities have the highest impact?), organizational structure (who is responsible?), and goals (to track the continuous improvement of sustainability performance).

Life Cycle Thinking The modeling method should by design guide the user in taking a life cycle perspective and provide the possibility to collect multiple indicators and model the life cycle of an organization.

Two-Layered Structure Existing business process modeling languages have different strengths and weaknesses, and design requirements like expressiveness, simplicity and formal analysis capability may be in conflict. For conventional BPM, Koschmider et al. [13] have proposed a two-layered structure, where a presentation layer is designed for cognitive effectiveness [16] and geared towards the needs of a specific user group. This presentation layer is then mapped to a lower layer that may leverage the advantages of formal modeling languages like Petri Nets. Furthermore, Petri Nets appear as an appropriate link between BPM and LCA, as they have been used in both disciplines (see [14], [7]).

The author has developed a web-based software prototype that exemplifies the idea of a POLCA modeling tool based on the above design principles. The current functionalities of this prototype encompass the collection of activities and formulation of sustainability goals with respect to indicators. To conclude the alpha cycle, the author is working on a systematic literature review to strengthen and elaborate the initial problem description. Subsequently, the concepts, requirements and metamodels are formalized and an initial modeling tool prototype will be extended accordingly.

\section{CONCLUSION AND FURTHER WORK}

This paper describes a research agenda for the development of a sustainable business process modeling method. It strives for an appropriate balance of rigor and relevance, by following established research methods and integrating practitioners. Immediate next steps are

- Conducting a tertiary study in the field of sustainable BPM. Several systematic literature reviews and mapping studies (e.g. [4], [23]) have been published, and may inform a modeling language design.

- Extension of the alpha version of the POLCA modeling tool as a basis for a first formative evaluation.

The results of the formative evaluation will then inform a second development cycle that results in a beta version of the POLCA modeling tool.

\section{REFERENCES}

[1] Stefanie Betz, Andreas Fritsch, and Andreas Oberweis. 2017. TracyML - A Modeling Language for Social Impacts of Product Life Cycles. In Proceedings of the ER Forum 2017. Valencia, Spain, 193-206. http://ceur-ws.org/Vol-1979/paper03.pdf

[2] Anders Bjørn, Mikołaj Owsianiak, Christine Molin, and Michael Z. Hauschild. 2018. LCA History. In Life Cycle Assessment. Springer International Publishing, Cham, Switzerland, 17-30. https://doi.org/10.1007/978-3-319-56475-3_3

[3] Guido Van Capelleveen, Johanna Pohl, Andreas Fritsch, and Daniel Schien. 2018. The Footprint of Things: A hybrid approach towards the collection, storage and distribution of life cycle inventory data. In 5th International Conference on Information and Communication Technology for Sustainability. Toronto, Canada, 350-364.

[4] Dries Couckuyt and Amy Van Looy. 2019. Green BPM as a Business-Oriented Discipline: A Systematic Mapping Study and Research Agenda. Sustainability 11, 15 (2019), 4200. https://doi.org/10.3390/su11154200

[5] John Elkington. 1998. Partnerships from cannibals with forks: The triple bottom line of 21st-century business. Environmental Quality Management (1998), 37-51.

[6] Ulrich Frank. 2013. Domain-specific modeling languages: Requirements analysis and design guidelines. In Domain Engineering: Product Lines, Languages, and Conceptual Models. Springer, Berlin, Heidelberg, 133-157. https://doi.org/10. 1007/978-3-642-36654-3_6

[7] Reinout Heijungs and Sangwon Suh. 2002. The Computational Structure of Life Cycle Assessment. Springer Science \& Business Media, Dordrecht, Netherlands.

[8] Y. Anny Huang, Christopher L. Weber, and H. Scott Matthews. 2009. Categorization of Scope 3 Emissions for Streamlined Enterprise Carbon Footprinting. Environmental Science and Technology 43, 22 (2009), 8509-8515. https: //doi.org/10.1021/es901643a

[9] Life Cycle Initiative, United Nations Environment Programme, and Society for Environmental Toxicology and Chemistry. 2015. Guidance on Organizational Life Cycle Assessment. UNEP, Paris, France. http://www.lifecycleinitiative.org/wpcontent/uploads/2015/04/o-lca \{_\}24.4.15-web.pdf

[10] International Organization for Standardization. 2014. ISO/TS 14072: Environmental management - Life cycle assessment- Requirements and guidelines for Organizational Life Cycle Assessment.

[11] Dimitris Karagiannis. 2015. Agile Modeling Method Engineering. In Proceedings of the 19th Panhellenic Conference on Informatics. 5-10. https://doi.org/10.1145/ 2801948.2802040

[12] Dimitris Karagiannis and Harald Kühn. 2002. Metamodelling Platforms. In Proceedings of the Third International Conference EC-Web. Aix-en-Provence, France, 182-195. https://doi.org/10.1007/3-540-45705-4_19

[13] Agnes Koschmider, Timm Caporale, Michael Fellmann, Jonas Lehner, and Andreas Oberweis. 2015. Business Process Modeling Support by Depictive and Descriptive Diagrams. In Enterprise Modelling and Information Systems Architectures. 15-29.

[14] Agnes Koschmider, Andreas Oberweis, and Wolffried Stucky. 2018. A Petri net-based View on the Business Process Life-Cycle. Enterprise Modelling and Information Systems Architectures (EMISA7) 13 (2018), 47-55.

[15] Julia Martínez-Blanco, Annekatrin Lehmann, Ya-Ju Chang, and Matthias Finkbeiner. 2015. Social organizational LCA (SOLCA)-a new approach for implementing social LCA. The International fournal of Life Cycle Assessment 20, 11 (2015), 1586-1599. https://doi.org/10.1007/s11367-015-0960-1

[16] Daniel Moody. 2009. The physics of notations: Toward a scientific basis for constructing visual notations in software engineering. IEEE Transactions on Software Engineering 35, 6 (2009), 756-779. 
[17] Matthew T. Mullarkey and Alan R. Hevner. 2019. An elaborated action design research process model. European fournal of Information Systems 28, 1 (2019), 6-20. https://doi.org/10.1080/0960085X.2018.1451811

[18] Mario Nolte, Monika Kaczmarek-Heß, Andreas Fritsch, and Stefanie Betz. 2019. A Hierarchy of DSMLs in Support of Product Life-Cycle Assessment. 14th International Conference on Wirtschaftsinformatik (2019), 1433-1447.

[19] Alexander Nowak and Frank Leymann. 2013. Green Business Process Patterns Part II (Short Paper). In 6th International Conference on Service-Oriented Computing and Applications. IEEE, 168-173. https://doi.org/10.1109/SOCA.2013.11

[20] Alexander Nowak, Frank Leymann, Daniel Schleicher, David Schumm, and Sebastian Wagner. 2011. Green Business Process Patterns. In Proceedings of the 18th Conference on Pattern Languages of Programs. ACM Press, New York, New York, USA, 1-10. https://doi.org/10.1145/2578903.2579144

[21] Michael Rosemann. 2006. Potential pitfalls of process modeling: part A. Business Process Management fournal 12 (2006), 249-254. Issue 2.
[22] Frank Schönthaler, Gottfried Vossen, Andreas Oberweis, and Thomas Karle. 2012. The Horus Method. In Business Processes for Business Communities. Springer, Berlin, Heidelberg, 61-136. https://doi.org/10.1007/978-3-642-24791-0_4

[23] Thorsten Schoormann, Dennis Behrens, and Ralf Knackstedt. 2017. Sustainability in Business Process Models: A Taxonomy-Driven Approach to Synthesize Knowledge and Structure the Field. In Proceedings of the Thirty Eighth International Conference on Information Systems.

[24] Stefan Seidel, Jan vom Brocke, and Jan C Recker. 2011. Call for action: investigating the role of business process management in green IS. Sprouts: Working Papers on Information Systems 11, 4 (2011).

[25] Maung K. Sein, Ola Hendridsson, Sandeep Purao, Matti Rossi, and Rikard Lindgren. 2011. Action Design Research. MIS Quarterly 35, 1 (2011), 47-56.

[26] John Venable, Jan Pries-Heje, and Richard Baskerville. 2012. A comprehensive framework for evaluation in design science research. In International Conference on Design Science Research in Information Systems and Technology. Las Vegas, NV, USA, 423--438. https://doi.org/10.1007/978-3-642-29863-9_31 